\title{
Foetal macrosomia: risk factors, maternal and foetal outcome in n'djamena mother and child hospital, chad
}

Volume 9 Issue 3 - 2018

\section{Introduction}

Foetal macrosomia has been defined in different ways. There are considerable variations of the minimum weight that defines macrosomia. ${ }^{1-3}$ The most satisfactory definitions are a birth weight above the 90th percentile corrected for gestational age and sex or a birth weight of $4000-4500 \mathrm{~g}$. Due to the variation of the minimum weight that defines macrosomia, reports of its incidence vary from $3 \%$ to $15 \% .{ }^{4}$ The incidence also varies with ethnicity. Studies have shown that Chinese and South Asian infants are smaller for their gestational age. ${ }^{5}$ Differences in birth weight distributionare probably due to the genetic and anthropometric factors. ${ }^{6}$ Macrosomia is recognized as a cause of foetal and maternal morbidity and mortality. ${ }^{4}$

Risk factors for macrosomia include high maternal body mass index and weight gain, advanced maternal age, multiparity, diabetes mellitus, and gestational age $>41$ weeks. ${ }^{7}$ However, it is well known that prediction based on clinical risk factors alone has a very low positive predictive value. ${ }^{?}$

The aim of this study was to determine the incidence of foetal macrosomia and macrosomia-associated maternal morbidity and mortality during a 6 months study at N'Djamena Mother and Child Hospital.

\section{Patients and method}

This was a prospective descriptive and analytical study covering the six months from January to June 2016. Our sample consisted of two groups: The study group were mothers who delivered macrosomic babies. We included all live newborn singleton macrosomic who were delivered at or greater than 37 week' gestation and who had no clinical evidence of congenital malformations. The control group were mothers who delivered a baby with a normal weight. These births were recorded after every macrosomia so there were an equal number of mothers in each group.

Demographic data including age, parity, and birth weight were recorded. The outcomes of interest were foetal and maternal complications. Data analysis was done by Epi info 6.0 French. Chisquare $\left(\mathrm{X}^{2}\right)$ test $(\mathrm{p}<0.05)$ was used to compare variables.

\section{Results}

Out of 5,284 deliveries during the study period, 403 babies weighed $4.0 \mathrm{~kg}$ and above. So the incidence of macrosomia was $7.6 \%$.

\section{Maternal characteristics}

The mean maternal age and mean birth parity of the study group was significantly greater than the control group. There were significantly more mothers with a previous history of foetal macrosomia in the study group than in the control group (Table 1).

\author{
Gabkika Bray Madoue,' Souan Nguele Sile, ${ }^{2}$ \\ Foumsou Lhagadang,' Abdelsalam Saleh' \\ 'Department of Gynaecology and Obstetrics, N?Djamena \\ Mother and Child Hospital, Chad \\ ${ }^{2}$ Department of Paediatrics, NDjamena Mother and Child \\ Hospital, Chad
}

\begin{abstract}
Correspondence: Gabkika Bray Madoue, Department of Gynaecology and Obstetrics, NaDjamena Mother and Child Hospital, Chad,Email abdulsani9@gmail.com
\end{abstract}

Received: November 26, 2017 | Published: May 3, 2018

Table I Maternal characteristics

\begin{tabular}{|c|c|c|c|}
\hline Maternal characteristics & $\begin{array}{l}\text { Study group } \\
(n=403)\end{array}$ & $\begin{array}{l}\text { Control group } \\
(n=403)\end{array}$ & P value \\
\hline Maternal age (years) & & & 0.02 \\
\hline Mean & $32.3 \pm 3.4$ & $26.7 \pm 4.1$ & \\
\hline Range & $18-43$ & $16-44$ & \\
\hline Mean parity & $4.5 \pm 2.8$ & $2.3 \pm 1.7$ & 0.04 \\
\hline $\begin{array}{l}\text { Previous history of foetal } \\
\text { macrosomia }\end{array}$ & 31.2 & 14.3 & 0.001 \\
\hline $\begin{array}{l}\text { Gestational age at delivery } \\
\text { (weeks) }\end{array}$ & & & 0.003 \\
\hline Mean & $41.7 \pm 2.5$ & $37.9 \pm 2.9$ & \\
\hline Range & $37-43$ & $37-42$ & \\
\hline Diabetes mellitus & $27(6.7 \%)$ & $5(1.2 \%)$ & 0.0001 \\
\hline
\end{tabular}

\section{Delivery mode}

Table 2 Mode of delivery

\begin{tabular}{lllll}
\hline $\begin{array}{l}\text { Mode of } \\
\text { delivery }\end{array}$ & $\begin{array}{l}\text { Spontaneous } \\
\text { vaginal }\end{array}$ & $\begin{array}{l}\text { Cesarean } \\
\text { section }\end{array}$ & $\begin{array}{l}\text { Operative } \\
\text { vaginal }\end{array}$ & Total \\
\hline & $\mathrm{n}(\%)$ & $\mathrm{n}(\%)$ & $\mathrm{n}(\%)$ & $\mathrm{n}(\%)$ \\
$\begin{array}{l}\text { Macrosomic } \\
\text { (study group) }\end{array}$ & $285(70.7)$ & $93(23.1)$ & $25(6.2)$ & $403(100)$ \\
$\begin{array}{l}\text { Control group } \\
324(80.4)\end{array}$ & $35(8.7)$ & $44(10.9)$ & $403(100)$ \\
\hline
\end{tabular}

Table 2 shows that $21.1 \%$ of mothers in the study group had delivered by caesarean versus $8.7 \%$ in the control group

Maternal complications: The commonest maternal complication in the macrosomic group was postpartum haemorrhage, followed by prolonged labour and perineal laceration-mainly first-and seconddegree laceration (Table 3). 
Table 3 Maternal complications

\begin{tabular}{llll}
\hline Maternal outcome & $\begin{array}{l}\text { Study group } \\
(\mathbf{n = 4 0 3 )}\end{array}$ & $\begin{array}{l}\text { Control group } \\
(\mathbf{n = 4 0 3 )}\end{array}$ & P value \\
\hline & $\mathrm{n}(\%)$ & $\mathrm{n}(\%)$ & \\
Postpartum haemorrhage & $64(15.9 \%)$ & $35(8.7 \%)$ & 0.003 \\
Perineallaceration & $18(4.4 \%)$ & $7(1.7 \%)$ & 0.027 \\
Prolonged labour & $56(13.9 \%)$ & $23(5.7 \%)$ & 0.002 \\
\hline
\end{tabular}

Foetal outcome: Table 4 shows that the male/female ratio of the neonates was sifnificantly higher among the macrosomic group than the control group $(\mathrm{p}=0.037)$ There was a significantly higher Proportion of macrosomic babies with an Apgar score below seven in the first and in the fifth minute compare to normal babies $(\mathrm{p}=0.0009)$.

Table 4 Differences in foetal outcome

\begin{tabular}{llll}
\hline Foetal outcome & $\begin{array}{l}\text { Study group } \\
(\mathbf{n = 4 0 3 )}\end{array}$ & $\begin{array}{l}\text { Control group } \\
(\mathbf{n}=403)\end{array}$ & P value \\
\hline Sex: male & $245(60.8 \%)$ & $20 \mathrm{I}(49.9 \%)$ & 0.037 \\
Apgar score Ist minute $(<7)$ & $26(6.9 \%)$ & $\mathrm{II}(2.7 \%)$ & $0.0 \mathrm{I}$ \\
Apgar score 5th minute $(<7)$ & $\mathrm{I} 5(3.7 \%)$ & $5(\mathrm{I} .2)$ & 0.025 \\
Stillbirth rate & $3(0.7 \%)$ & $\mathrm{II}(2.7 \%)$ & 0.032 \\
Shoulder dystocia & $5(\mathrm{I} .2 \%)$ & $0(0 \%)$ & 0.025 \\
Hypoglycaemia & $34(8.4 \%)$ & $\mathrm{II}(2.7 \%)$ & 0.0006 \\
\hline
\end{tabular}

There were $5(1.3 \%)$ cases of shoulder dystocia in the macrosomic subjects and none in the control group. No foetal births injuries occurred.

There were three stillbirths $(0.7 \%)$ in the study group and $11(2.7 \%)$ in the control group .A difference that was statistically significant $(p=$ 0.032 ).

There were $34(8.4 \%)$ cases of hypoglycaemia in the macrosomic neonates and $11(2.7 \%)$ in the control group.

\section{Discussion}

\section{Incidence and risk factors}

The incidence of foetal macrosomia in this study was $7.6 \%$. A Nigerian investigation reported $8.1 \% .{ }^{8}$ The highest reported incidence is $20 \%$ in Nordic countries. ${ }^{9}$ These figures are influenced by race and local factors. ${ }^{8}$ The pathophysiology of macrosomia is related to the associated maternal or foetal conditions poorly controlled diabetes mellitus, maternal obesity, and excessive maternal weight gain. All of which have intermittent periods of hyperglycaemia.

Our study showed that mothers of macrosomic neonates were significantly older which agrees with other reports. ${ }^{8,10}$ Grandmultiparity was found to be strongly associated with foetal macrosomia. These findings are in keeping with those of Mutihir. ${ }^{11}$ and Ezegwui. ${ }^{8}$ who showed that there was a higher proportion of multiparity among mothers of macrosomic neonates.

This study demonstrated that a large population of women delivering macrosomic infants had previous a history of delivering a macrosomic infant. Women who previously delivered macrosomic babies are 5-9times more likely to deliver a baby considered largefor-gestational age in subsequent pregnancies. ${ }^{12}$

We found a greater proportion of diabetic mothers among the study group than in the control group. Foetal macrosomia in diabetic mothers has been attributed to poor glucose control. Hyperglycaemia in the foetus results in the stimulation of insulin, insulin like growth factors, growth hormone, and other growth factors, which stimulate foetal growth and deposition of fat and glycogen.

Macrosomia is associated with a higher incidence of Caesarean section delivery (double that among the control subjects) and with birth canal lacerations associated with vaginal delivery. ${ }^{13,14}$ This was confirmed in this study with a Caesarean section rate of $23.1 \%$ versus $8.7 \%$ in the control group. The risk of Caesarean section escalates with increasing birth weight, and the proportion of vaginal instrumental delivery decreases with increasing birth weight. ${ }^{15,16}$ The increased Caesarean section rate is a consistent finding in different countries and in different ethnic groups, and the odds are particularly high for primiparous mothers. ${ }^{15}$ In macrosomic births, the risk of shoulder dystocia is associated with the need for vaginal instrumental delivery. ${ }^{16}$

\section{Maternal complications}

Macrosomia was strongly associated with prolonged pregnancy in the study. This was comparable to the findings of Mutihir. ${ }^{11}$ and Spellacy. ${ }^{13}$ who observed that macrosomic infants account for about $1 \%$ of term deliveries and $3-10 \%$ of post-term deliveries. Advanced gestational age results in a larger birth weight. Macrosomia occurs with higher frequency in prolonged pregnancies. This is to be expected as infants gain approximately $150-200 \mathrm{~g}$ weekly near term. The duration of labour is more prolonged for women carrying macrosomic babies, and the risk is increased with increasing birth weight. ${ }^{15}$ Both the first and second stages of labour are longer than for normosomic pregnancies, and arrest of descent in the second stage of labour is associated with macrosomia. ${ }^{15}$ Our findings confirm this assertion with the higher prolonged labour in the study group $(19.9 \%$ versus 5.7\%).Macrosomia had been reported as a risk factor for post partum haemorrhage. ${ }^{16,17}$ a fact confirmed in our study.

\section{Foetal outcome}

Male infants are more likely to be macrosomic than female infants. Male infants are generally 150-200g larger than female infants of the same gestational age near term.

Although the literature frequently and consistently demonstrates an increase in perinatal morbidity and mortality with increasing birth weight, the overall incidence of neonatal complications remains low. ${ }^{18}$

We had noted a higher proportion of newborns with bad Apgar scores in the study group compared with the control group. Ezegwui. ${ }^{8}$ also reported a higher proportion of newborns with bad Apgar scores in their study group. The greater the birth weight, the higher the risk of low Apgar scores.

More newborns with hypoglycaemia were found in the study group. The risk of neonatal hypoglycaemia is higher in heavy babies. ${ }^{19}$ Neonates with a birth weight $>4,500 \mathrm{~g}$ had a seven-fold higher risk of having neonatal hypoglycaemia, compared with those with an appropriate weight for gestation age. ${ }^{20}$ This risk further increases in the presence of gestational diabetes.

Five shoulder dystocia were noted in the study group versus none in the control group. It has been reported consistently in the literature that the risk of shoulder dystocia escalates with increasing birth weight. ${ }^{20}$ However; the incidence of shoulder dystocia in different birth weight groups varies widely between studies. ${ }^{20}$

\section{Conclusion}

This study had shown that the delivery of macrosomic neonates is 
anusual activity in our hospital. The risk factors are the same reported as in the literature. The commonest delivery mode is vaginal despite a high proportion of Caesarean section. Main maternal complications are post partum haemorrhage, prolonged labour and perineal laceration. Foetal outcome are a bad Apgarscore, hypoglycaemia, shoulder dystocia and stillbirth. There is a clear need during prenatal care and delivery to minimise maternal and foetal complications.

\section{Acknowledgements}

None.

\section{Funding}

No financial assistance or grants were solicited or obtained during the course of preparing this article.

\section{Consent}

We obtained consent of patients and agreement of the Director of N'Djamena Mother and Child Hospital.

\section{Conflict of interest}

Author declares there is no conflict of interest in publishing the article.

\section{References}

1. Handa VL, Danielsen BH, Gilbert WM. Obstetric and Sphincter lacerations. Obstet Gynecol. 2001;98(2):225-230.

2. Henriksen T. The macrosomic fetus: A challenge in current obstetrics. Acta Obstet Gynecol Scand. 2008;87(2):134-145.

3. ACOG Practice Bulletin No 22: Fetal macrosomia. Washington DC: American College of Obstetricians and Gynecologists; 2000.

4. Koyanagi A, Zhang J, Dagvadorj A, et al. Macrosomia in 23 developing countries: an analysis of a multi country, facility-based, cross-sectional survey. Lancet. 2013;381(9865):476-483.

5. Cheng YK, Lao TT, Sahota DS, et al. Use of birth weight threshold for macrosomia to identify fetuses at risk of shoulder dystocia among Chinese populations. Int J Gynaecol Obstet. 2013;120(3):249-253.

6. Wang X, Guyer B, Paige DM. Differences in gestational age-specific birth weight among Chinese, Japanese and white Americans. Int $J$ Epidemiol. 1994;23(1):119-128.
7. Stotland NE, Caughey AB, Breed EM, et al. Risk factors and obstetric complications associated with macrosomia. Int J Gynaecol Obstet. 2004;87(3):220-226.

8. Ezegwui HU, Ikeako LC, Egbuji C. Fetal macrosomia: Obstetric outcome of 311 cases in UNTH, Enugu, Nigeria. Niger J Clin Pract. 2011;14(3):322-326.

9. Henriksen T. The macrosomicfetus: A challenge in current obstetrics. Acta Obstet Gynecol Scand. 2008;87(2):134-145.

10. Akin Y, Comert S, Turanc C, et al. Macrosomic newborns: A 3-year review. Turk J Pediatr. 2010;52(4):378-82.

11. Mutihir JT, Ujah IA. Post maturity and fetal macrosomia in Jos, Nigeria. Annals of African Medicine. 2005;4(2):72-76.

12. Voldner N, Qvigstad E, Froslie KF, et al. Increased risk of macrosomia among overweight women with high gestational rise in fasting glucose. $J$ Matern Fetal Neonatal Med. 2010;23(1):74-81.

13. Spellacy WN, Miller S, Winegar A, et al. Macrosomia--maternal characteristics and infant complications. Obstet Gynecol. 1985;66(2):158-161.

14. Cheng YK, Lao T. Fetal and maternal complications in macrosomic pregnancies. Research \& Reports Neonatology. 2014;4:65-70.

15. Boulet SL, Alexander GR, Salihu HM, et al. Macrosomic births in the United States: determinants, outcomes, and proposed grades of risk. $\mathrm{Am}$ J Obstet Gynecol. 2003;188(5):1372-1378.

16. Weissmann-Brenner A, Simchen MJ, Zilberberg E, et al. Maternal and neonatal outcomes of macrosomic pregnancies. Med Sci Monit 2012;18(9):PH77-PH81.

17. Gabkika BM, Djongali S, Oumarou GS, et al. Immediate post-partum haemorrhage: Epidemiological aspects and maternal prognosis at South N'djamena District Hospital (Chad). South Sudan Medical J. 2015; $8(2): 32-36$.

18. Gregory KD, Henry OA, Ramicone E, et al. Maternal and infant complications in high and normal weight infants by method of delivery. Obstet Gyencol. 1998;92(4 Pt 1):507-513.

19. Esakoff TF, Cheng YW, Sparks TN, et al. The association between birth weight $4000 \mathrm{~g}$ or greater and perinatal outcomes in patients with and without gestational diabetes mellitus. Am J Obstet Gynecol. 2009;200(6):672.e1-e4.

20. Karimu AL, Ayoade G, Nwebube NI. Arrest of descent in second stage of labour secondary to macrosomia: a case report. J Obstet Gynaecol Can. 2003;25(8):668-670. 